\title{
Radiographic manifestations of eosinophilic gastroenteritis
}

\author{
K. M. Vitellas, ${ }^{1}$ W. F. Bennett, ${ }^{1}$ J. G. Bova, ${ }^{1}$ J. C. Johnson, ${ }^{1}$ J. K. Greenson, ${ }^{2}$ J. H. Caldwell ${ }^{3}$ \\ ${ }^{1}$ Department of Radiology, Ohio State University Medical Center, Rm. S-209, Rhodes Hall, 450 W. 10th Ave., Columbus, OH 43210, USA \\ ${ }^{2}$ Department of Pathology, University of Michigan Hospitals, Ann Arbor, MI, USA \\ ${ }^{3}$ Division of Gastroenterology, Ohio State University Medical Center, Columbus, OH 43210, USA
}

Received: 24 February 1994/Accepted after revision: 18 July 1994

\begin{abstract}
Eosinophilic gastroenteritis (EG) is a rare inflammatory disease of unknown etiology, characterized by focal or diffuse eosinophilic infiltration of the gastrointestinal tract. Although little over 250 cases of EG have been reported in the literature, EG is probably more common than reports in the literature would indicate. A retrospective review of 25 patients with EG along with a review of the literature was done to identify clinical, laboratory, radiographic, and therapeutic features. An allergic disorder was present in $14(56 \%)$ and a peripheral eosinophilia was present in $24(96 \%)$ of our patients. The most common radiographic manifestations of the stomach and small bowel included stenosis and fold thickening, respectively. Thirteen patients had esophageal involvement, with the esophageal stricture being the most common abnormality found in these patients. Steroids produced a good therapeutic result in most patients; the remaining patients responded to cromolyn and/or surgery.
\end{abstract}

Key words: Gastroenteritis-Eosinophilia-Allergy-Barium studies.

Eosinophilic gastroenteritis (EG) is an inflammatory disease of unknown etiology characterized by focal or diffuse eosinophilic infiltration of the gastrointestinal tract, with clinical and radiographic manifestations related to the location and layer of tissue involvement. The clinical course is chronic and characterized by exacerbations and remissions, with steroids providing a rapid relief of symptoms in most patients. This disease

Presented at the ARRS 94th Annual Meeting, New Orleans, Louisiana, USA, April 24-29, 1994; received Bronze Medal Award

Correspondence to: $\mathrm{K}$. M. Vitellas can affect any part of the gastrointestinal tract but usually involves the stomach and small bowel. An allergic diathesis is the proposed mechanism because most patients with this disease demonstrate a hypersensitivity syndrome, peripheral eosinophilia, and a rapid response to steroid therapy. Although little more than 250 cases of EG have been reported in the literature, EG is probably more common than reports in the literature would indicate. The goal of this paper is to review the EG literature and include our experience with 25 patients with EG, which is the largest, single-institution experience in the radiology literature, so that physicians will become more aware and suggest the diagnosis in the appropriate clinical setting. This will avoid the morbidity associated with a delay in diagnosis.

\section{Pathophysiology}

Although the etiology of EG is unknown, an allergic or immunologic disorder is the most common proposed cause for this disease, and evidence for this etiology stems from findings that include (1) a peripheral eosinophilia in 79\% of patients [1]; (2) evidence of eosinophilic infiltration of the gastrointestinal tract; (3) the presence of an allergic diathesis (asthma, allergic rhinitis, hay fever, atopic dermatitis, eczema, urticaria, food allergy, or medicine allergy) in approximately $50 \%$ of patients [2-5]; (4) the resolution of symptoms with corticosteroid therapy in more than $90 \%$ of patients [1]; (5) elevated IgE in some patients [6]; and (6) symptomatic response to specific food elimination and food challenge $[2,6]$.

The eosinophil is a normal component of the gastrointestinal tract [7] and is found in increased numbers in many diseases including inflammatory bowel disease, peptic ulcer disease, Hodgkin's lymphoma, carcinoma, and parasitic infestation. In EG, the concentration of 


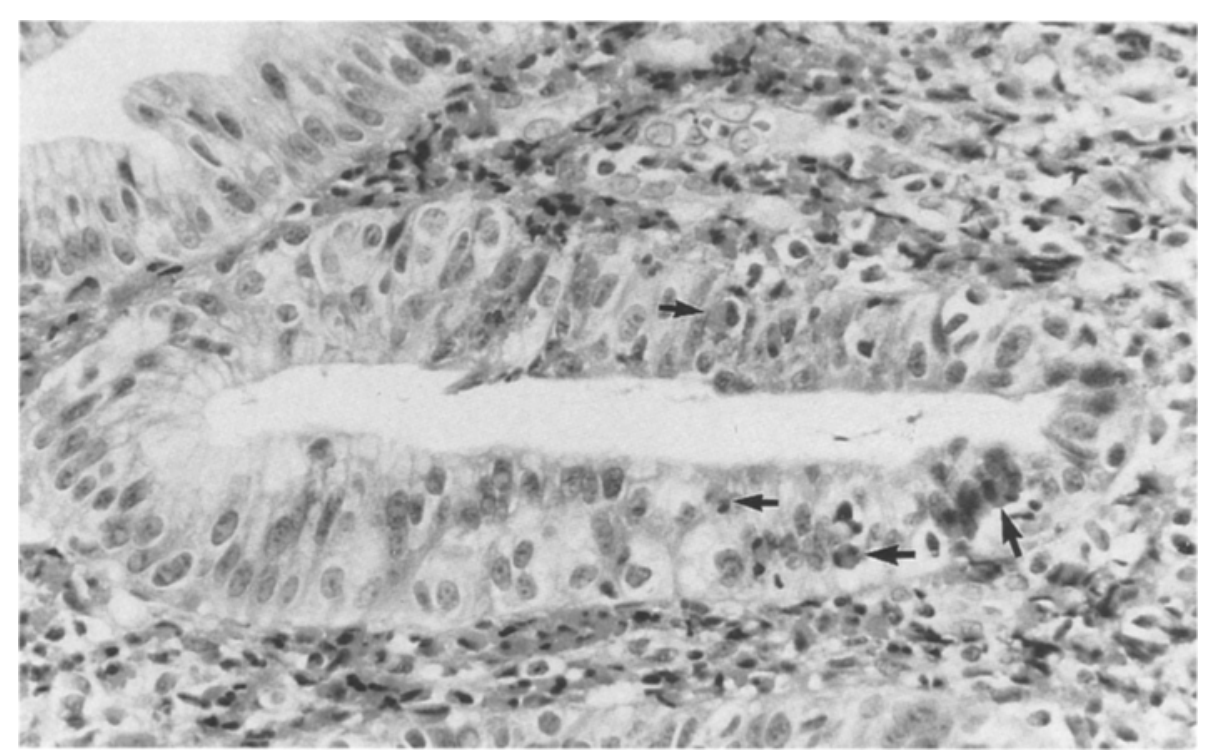

Fig. 1. Photomicrograph of an endoscopic mucosal biopsy of the gastric antrum in a patient with predominant mucosal disease shows large numbers of eosinophils within the mucosa (arrows) and lamina propria (H\&E; high power). eosinophilic infiltration is more pronounced $[4,7,8]$ a characteristic that may be helpful in separating this disease from other causes of gastrointestinal eosinophilia. However, because the gastrointestinal tract is involved in a patchy distribution of eosinophils, and because more than one tissue layer can be involved at the same time, it is difficult to quantify accurately the degree of gastrointestinal eosinophilia in most patients [9]. Eosinophilic infiltration of the esophagus is most commonly found in association with reflux esophagitis [10], and it is important to exclude this condition before a diagnosis of eosinophilic esophagtitis (EE) can be made, especially if a distal esophageal abnormality is encountered.

All three histologic layers (mucosa, muscularis, subserosa) of the gastrointestinal tract are involved to varying degrees; however, one layer is predominantly involved, allowing for characteristic symptoms and radiographic manifestations. The Klein classification separates EG into three groups according to the predominant tissue layer of involvement: (1) predominant mucosal disease, defined as infiltration of the mucosa by eosinophils (Fig. 1) and/or evidence of mucosal edema on contrast studies or endoscopy, with no evidence of gastrointestinal obstruction or eosinophilic ascites; (2) predominant disease of the muscularis, defined as evidence of gastrointestinal stenosis or obstruction on contrast studies and/or eosinophilic infiltration of the gastrointestional tract without evidence of eosinophilic ascites; and (3) predominant subserosal disease, defined as eosinophilic infiltration of the gastrointestinal tract and eosinophilic ascites. Talley et al. [3] used the Klein classification to group 40 patients with EG, demonstrating predominant mucosal disease in $23(57.5 \%)$, predominant muscularis disease in $12(30 \%)$, and predominant subserosal disease in $5(12.5 \%)$ patients. Our series showed similar results with predominant mucosal disease in $10(48 \%)$, predominant muscularis disease in $7(33 \%)$, and predominant subserosal disease in $4(19 \%)$ patients. Four of our patients could not be categorized according to the Klein classification because of isolated esophageal involvement without extra-esophageal gastrointestinal involvement and were placed in the EE category. Because the eosinophilic infiltration occurs in a patchy distribution and can involve more than one tissue layer simultaneously, endoscopic biopsy can give falsenegative results. This was illustrated in one of our patients with predominant muscularis disease, in whom endoscopic biopsy was negative; however, the clinical history of peripheral eosinophilia and allergic disorder, radiographic manifestations of stenosis of the small bowel, and clinical remission with steroid therapy proved the diagnosis.

\section{Clinical Aspects}

EG occurs usually during the third decade of life. There is no sex or race predilection as reported in the literature [11]; however, in our series, we found the male:female ratio to be 3:1 (19 men:6 women). An allergic or immunologic disorder is the most common proposed cause for this disease. A peripheral eosinophilia is reported to occur in $79 \%$ of patients [1] and occurred in $96 \%$ (24) of our patients. An allergic disorder (asthma, allergic rhinitis, food allergy, atopic dermatitis, eczema, urticaria, and/or medicine allergy) is reported to occur in approximately $50 \%$ of patients [2-5] and was present in $56 \%$ (14) of our patients.

The clinical manifestations of EG depend on the location and depth of tissue involvement. Patients with predominant mucosal disease present with nausea, vomiting, abdominal pain, diarrhea, and weight loss; pre- 

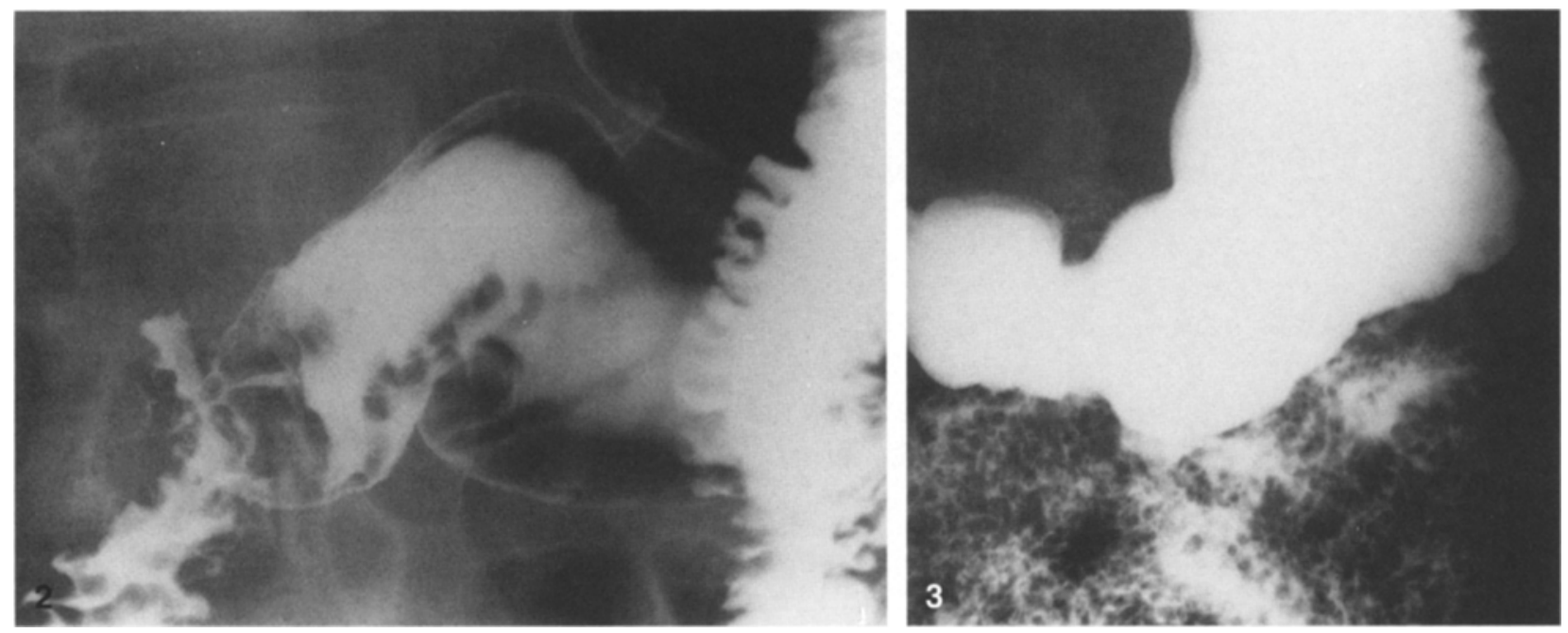

Fig. 2. Predominant mucosal disease. A 27-year-old man presented with abdominal pain and diarrhea. He had' a history of asthma and hay fever. Laboratory data revealed peripheral eosinophilia and hypoproteinemia. Endoscopic biopsy showed eosinophilic infiltration of the gastric antrum and duodenum. UGI with SBFT demonstrated fold thickening of the gastric antrum (above) and diffuse, uniform fold thickening of the jejunum. He had a partial clinical response to prednisone and complete remission with the addition of cromolyn.

Fig. 3. Prone UGI with SBFT spot film in another patient with predominant mucosal disease demonstrates diffuse, uniform nodularity of the jejunum.

creas [10], liver, and biliary tree $[11,20,21]$. In addition, bladder involvement [22], pericarditis [11], cholecystitis [11], and pleural effusions [9] have been associated with EG. The stomach alone is involved in approximately $40 \%$ of cases [1]; the stomach and small bowel both are involved in approximately $50 \%$ of cases; and the small bowel alone is involved in approximately $10 \%$ of cases.

Esophageal involvement in EG is very rare, and prior to our retrospective review, there were only 10 cases of $\mathrm{EE}$ reported in the literature. Our study showed that 13 patients $(52 \%)$ demonstrated esophageal involvement [14]. All patients had esophageal symptoms including dysphagia (12) and chest pain secondary to esophageal spasm (1). All patients were found to have eosinophilic infiltration of the esophagus. Nine patients (69\%) had esophageal disease in conjunction with extra-esophageal gastrointestinal disease, and 4 patients $(31 \%)$ had isolated esophageal involvement.

The diagnosis of EG is based on (1) biopsy evidence of eosinophilic infiltration of the gastrointestinal tract, (2) compatible gastrointestinal symptoms, and (3) the absence of parasitism and other diseases that may produce a peripheral eosinophilia and complicate the diagnosis. The presence of an allergic disorder or peripheral eosinophilia is not required to make the diagnosis. The diagnosis of EE is made in a similar fashion, with patients demonstrating esophageal symptoms and eosinophilic infiltration of the esophagus. However, gastroesophageal reflux disease is the most common cause of eosinophilic infiltration of the esophagus, so this disease must be excluded, and a trial of steroids may be the only means to differentiate the two processes. Patients with 
Table 1. Radiographic manifestations of the three classes of EG

\begin{tabular}{|c|c|}
\hline Classification & Radiographic findings \\
\hline Predominant mucosal disease & $\begin{array}{l}\text { Fold thickening } \\
\text { Polyps } \\
\text { Ulceration } \\
\text { Luminal narrowing } \\
\text { Hypersecretion } \\
\text { Irritability } \\
\text { Spasm } \\
\text { Areae gastricae } \\
\text { Esophageal abnormalities } \\
\quad \text { associated with EE }\end{array}$ \\
\hline Predominant muscularis disease & $\begin{array}{l}\text { Stenosis } \\
\text { Rigidity } \\
\text { Dysmotility } \\
\text { Any of the findings in } \\
\text { predominant mucosal } \\
\text { disease }\end{array}$ \\
\hline Predominant subserosal disease & $\begin{array}{l}\text { Eosinophilic ascites } \\
\text { Adherent loops of bowel } \\
\text { Omental and mesenteric } \\
\text { thickening } \\
\text { Eosinophilic } \\
\text { lymphadenopathy } \\
\text { Eosinophilic pleural } \\
\text { effusion } \\
\text { Any of the findings in } \\
\text { predominant mucosal } \\
\text { and/or muscularis disease }\end{array}$ \\
\hline
\end{tabular}

${ }^{a}$ Found in children with allergic gastroenteropathy.

${ }^{b}$ The hallmark of predominant subserosal disease.

EE will show a good clinical response to steroid therapy, whereas patients with reflux esophagitis will not respond to steroids. These criteria were followed in all patients except one who did not demonstrate eosinophilic infiltration of the gastrointestinal tract by endoscopic biopsy but had clinical, laboratory, radiographic, and therapeutic findings compatible with the diagnosis.

In the majority of patients, the disease follows a relatively benign course, punctuated by recurrent symptoms controlled by short-term corticosteroid therapy. Few patients are maintained on chronic steroid therapy, and some have self-limited recurrences [23, 24]. In addition, the radiographic manifestations may be completely reversible with steroid therapy [8]. Oral cromolyn has induced remission in some cases $[25,26]$, whereas elimination diets have generally been unsuccessful $[6,13,15,27]$. In our series, the resolution of symptoms was accomplished with steroids alone (20), surgery alone (3), steroids plus cromolyn (1), and cromolyn alone (1).

Significant morbidity is associated with a delay in diagnosis, including unnecessary surgery. Agertoft et al. [28] reviewed the literature and found seven cases of EG complicated by intestinal perforation. In addition, there have been four deaths attributed to EG, three following complications of surgery $[1,10,29,30]$.

In our series, 6 patients underwent exploratory laparotomy for abdominal pain of unknown etiology. The preoperative diagnosis of these patients included peptic stricture complicating peptic ulcer disease (3), peritonitis secondary to Crohn's disease (1), gastric carcinoma (1), and appendicitis (1). The diagnosis of EG was established by surgical biopsy in 4 patients and by postoperative endoscopic biopsy in 2 patients. Surgery alone was curative in 3 patients, and postoperative steroid therapy was successful in the remaining 3 patients. There were no operative or postoperative complications in these patients.

\section{Radiographic Findings}

\section{Predominant Mucosal Disease}

The radiographic manifestations include nonspecific mucosal fold thickening (the most common roentgenographic finding [8]; Figs. 2, 3), polyps, ulcerations, luminal narrowing, hypersecretion, irritability, spasm, areae gastricae, and esophageal abnormalities associated with EE (Table 1).

The radiographic manifestations of the pediatric patient with allergic gastroenteropathy are unique, as explained by Teele et al. [12] who found the diffuse, "lacy," antral mucosal pattern of areae gastricae in six children with allergic gastroenteropathy. In addition, they suggested that this lesion was the earliest radiographic manifestation of disease in children and that aircontrast examinations of the gastric antrum in all children suspected of having this disease should be performed to find this early mucosal pattern of the antrum (Fig. 4C). Although a normal pattern in adults [31], the radiographic manifestation of areae gastricae in children suggests the presence of gastritis associated with conditions such as corrosive ingestion, peptic ulcer disease, and Crohn's disease [12]. Other radiographic manifestations of allergic gastroenteropathy include various mucosal abnormalities also seen in EG of adults such as nonspecific mucosal edema, including fold and wall thickening (Fig. 4A,B) and esophageal strictures (Fig. 4D). Clinically, these children respond rapidly and dramatically to steroid therapy, and they have a better response to elimination diets than do adults with EG. In addition, this condition generally regresses as the child approaches adulthood [21].

The differential diagnosis of this class of EG involving the stomach and small bowel includes lymphoma, carcinoma, Zollinger-Ellison syndrome, amyloidosis, hypoproteinemia, regional enteritis, and pancreatitis. The differential diagnosis of this class involving only the stomach includes peptic gastritis, Menetrier's disease, and varices. The differential di- 


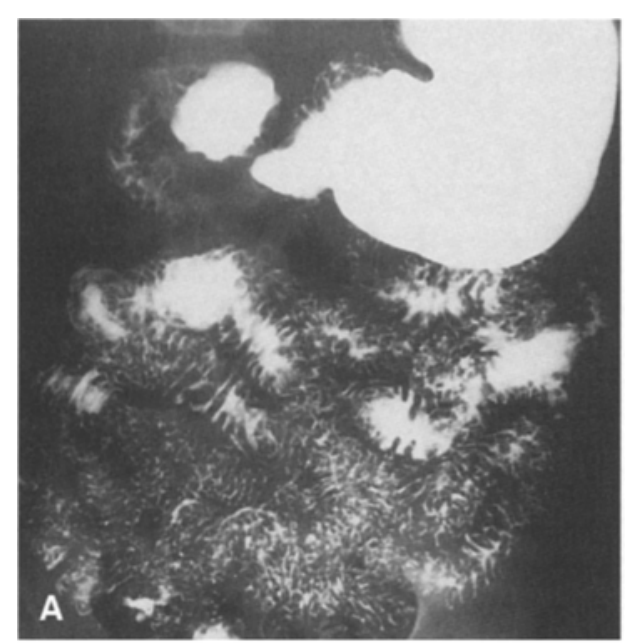

Fig. 4. Allergic gastroenteropathy. A 10-year-old boy presented with dysphagia, diarrhea, and multiple food allergies. Laboratory studies revealed peripheral eosinophilia and an elevated IgE. A peroral capsule biopsy demonstrated eosinophilic infiltration of the jejunum. Symptoms resolved with steroids and cromolyn. A Prone UGI with SBFT shows diffuse, uniform fold thickening of duodenal and jejunal folds. B Spot film of the duodenum reveals uniform fold thickening. $C$ Air-contrast spot film of the gastric antrum demonstrates the areae gastricae pattern. D Barium esophagram shows an elongated, 5$\mathrm{mm}$ caliber stricture of the proximal esophagus (arrowheads).
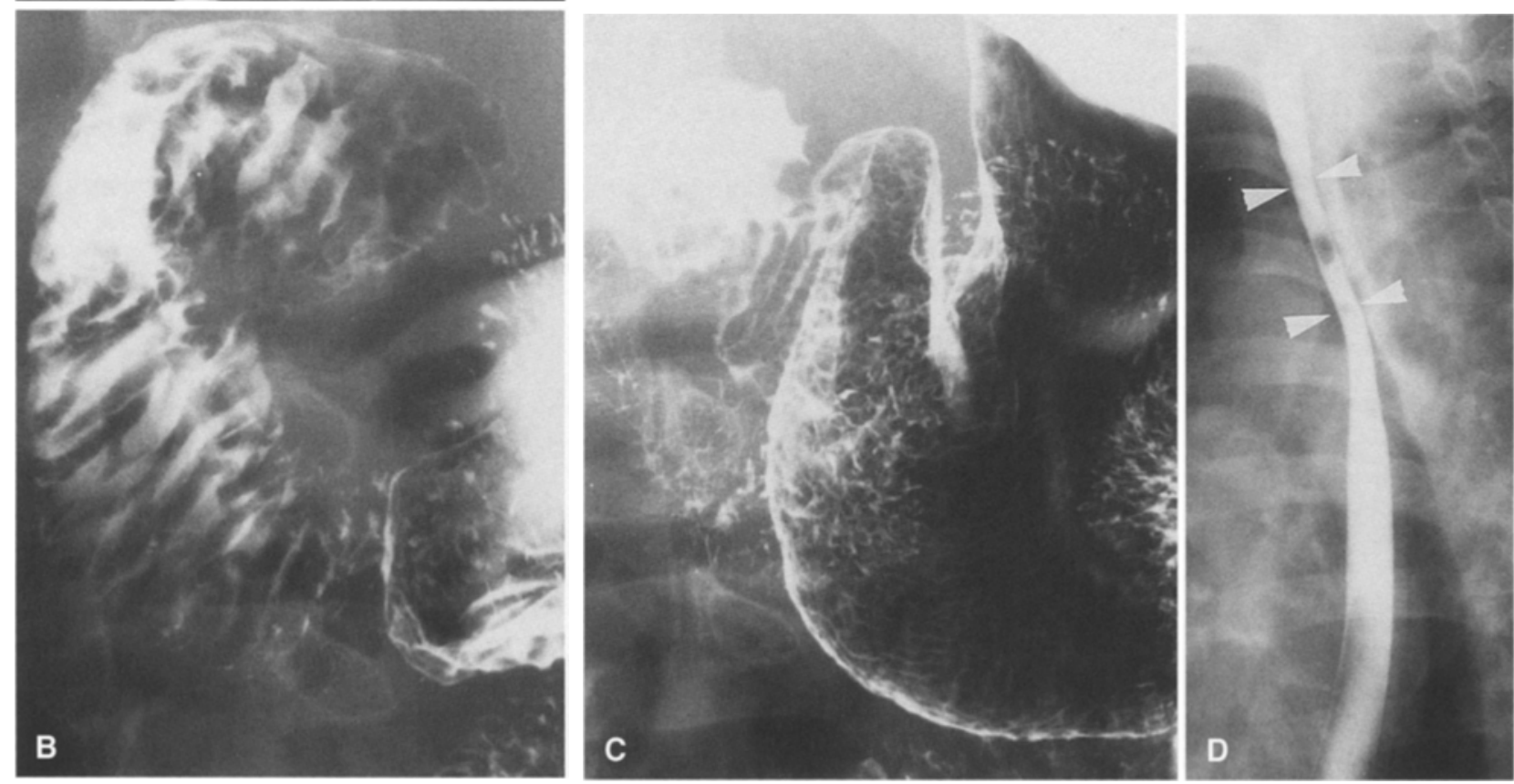

agnosis of this class involving only the small bowel includes regional enteritis, giardiasis, Waldenstrom's macroglobulinemia, lymphangiectasia, ischemia, and infarction.

\section{Predominant Muscularis Disease}

Radiographic findings include stenosis, rigidity (Figs. 5, 6), and dysmotility (Table 1), in addition to findings associated with predominant mucosal disease and EE. The antrum and/or proximal small bowel are most commonly involved [9].

The differential diagnosis of this class of EG involving the stomach and small bowel includes carcinoma, peptic ulcer disease, pancreatitis and pancreatic carcinoma, tuberculosis, lymphoma, amyloidosis, regional enteritis, metastases, and postirradiation strictures. The differential diagnosis of this class involving only the stomach includes acid ingestion, syphilis, and hypertrophic pyloric stenosis.

\section{Predominant Subserosal Disease}

In addition to eosinophilic ascites and findings associated with predominant mucosal and/or muscularis disease (Figs. 7, 8) and EE, subserosal disease may cause adherent loops of bowel, omental, and mesenteric thickening, eosinophilic lymphadenopathy and eosinophilic pleural effusion [9] (Table 1). Talley et al. [3] noted that patients with subserosal disease were different than patients from the other two groups in clinical presentation (abdominal bloating, ascites), higher eosinophil counts, and in their greater response to steroid therapy. 


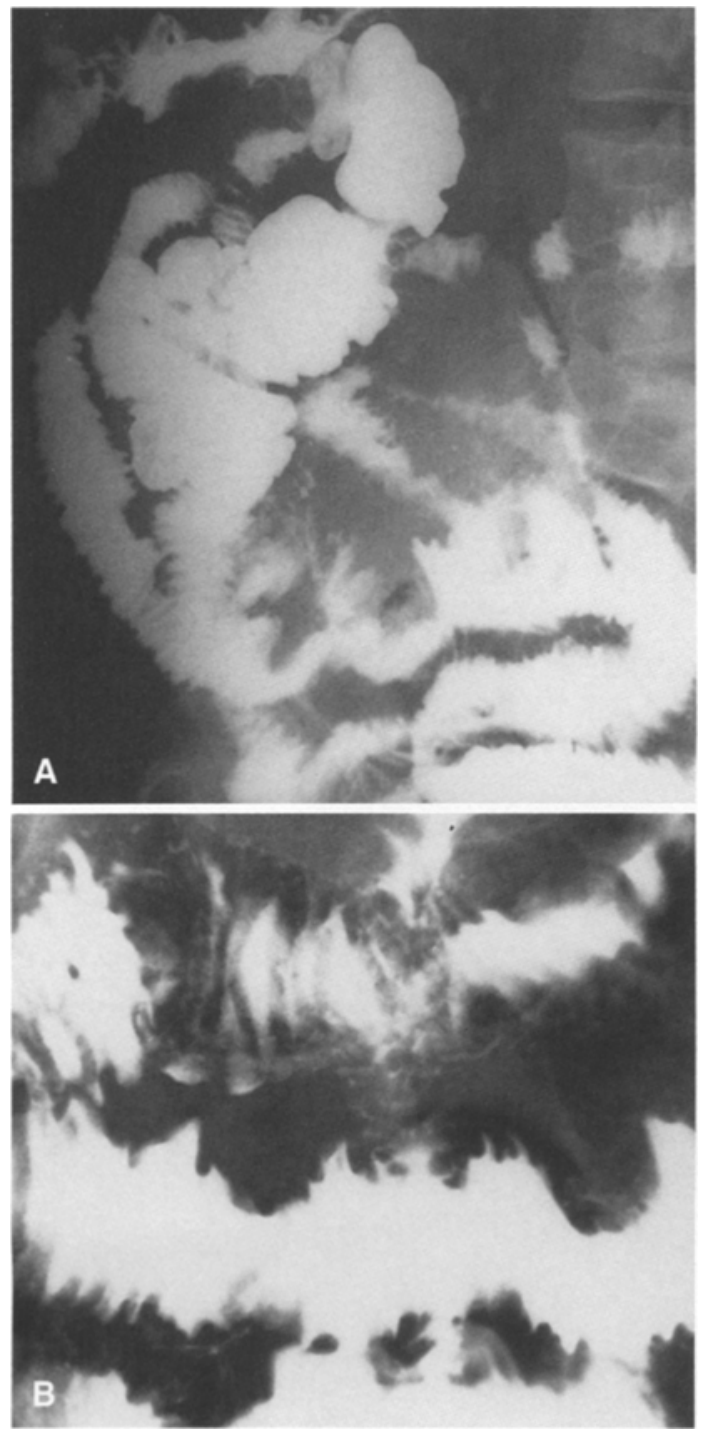

Fig. 5. Predominant muscularis disease. A 40-year-old man presented with dysphagia, abdominal pain, postprandial nausea, and vomiting. He had a history of eczema and multiple food allergies. Laboratory data revealed a peripheral eosinophilia, hypoproteinemia, and an elevated IgE. Endoscopic biopsy showed eosinophilic infiltration of the proximal esophagus, gastric antrum, and duodenum. He had a resolution of symptoms with steroid therapy. A RPO overhead view of a SBFT shows thickened folds and segmental stenosis of the small bowel with separation of bowel loops. Ascites was not demonstrated during clinical evaluation. B SBFT demonstrates fold thickening of the small bowel.

\section{Eosinophilic Esophagitis}

Prior to our retrospective review, only 10 cases of $\mathrm{EE}$ had been reported in the literature. Of the 25 patients we reviewed, 13 patients were found to have EE [14]. Esophagrams demonstrated strictures (10) and a cervical web (1). Esophageal manometry revealed dysmotility (3), and esophagogastroscopy demonstrated ulcers (2) and a mucosal ring (1).

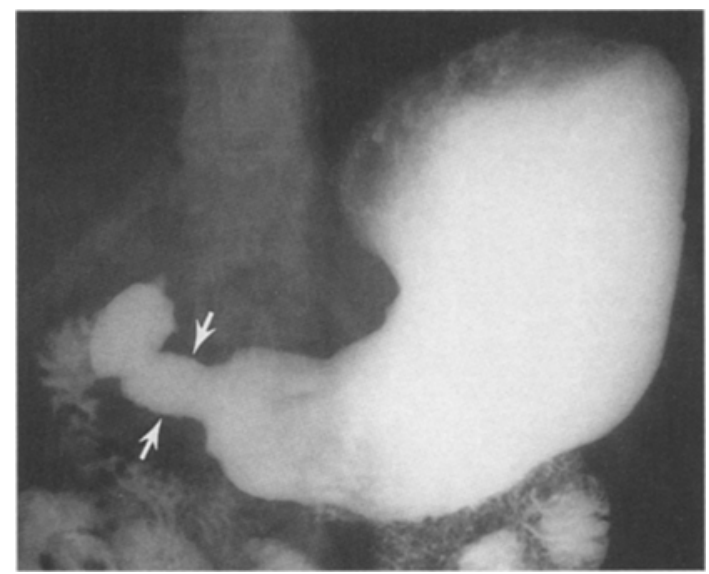

Fig. 6. Prone UGI radiograph in another patient with predominant muscularis disease demonstrates a slightly lobulated narrowing of the antrum (arrows), causing proximal gastric dilatation.

The stricture was the most common esophageal abnormality found in our study, occurring in 9 patients $(69 \%)$, with the proximal stricture occurring in $6(67 \%)$ (Figs. 4D, 9A). Two patients demonstrated distal esophageal strictures only, and 1 patient demonstrated both proximal and distal esophageal strictures. A variety of disorders are implicated in producing a proximal esophageal stricture (Table 2), including radiation esophagitis, caustic ingestion, medication-induced esophagitis, Barrett's esophagus, fungal infections, and certain skin disorders (e.g., pemphigoid and epidermolysis bullosa). In addition, it is interesting that current medical textbooks do not include EE as a cause of the proximal esophageal stricture, and it is important for the physician to incorporate this disease in the differential diagnosis. Reports have described esophageal strictures in 6 of 10 patients $(60 \%)$ with $2(33 \%)$ occurring in the proximal esophagus and $4(67 \%)$ in the distal esophagus [15, 16, 32-34]. Again, it is important to exclude reflux esophagitis in patients with eosinophilic infiltration of the esophagus, especially if a distal esophageal abnormality is present; a trial of steroid therapy may be the only means to confirm the diagnosis. None of our patients demonstrated hiatal hernia or gastroesophageal reflux during barium esophagram, nor did those undergoing esophagogastroscopy have findings characteristic of gastroesophageal reflux disease. All patients who received steroids had good results (Fig. 9).

In our patients, radiographic manifestations of the stomach included gastric stenosis (7), pyloric stenosis (5), gastric rigidity (3), gastric fold thickening (2), pyloric rigidity (2), delayed gastric emptying (2), wall thickening (1), gastric polyps (1), antral irregularity (1), and areae gastricae (1). Radiographic manifestations of the small bowel included fold thickening (12), wall thickening (5), stenosis (5), dilatation (4), separation of bowel loops (2), and hypersecretion (1). Radiographic 

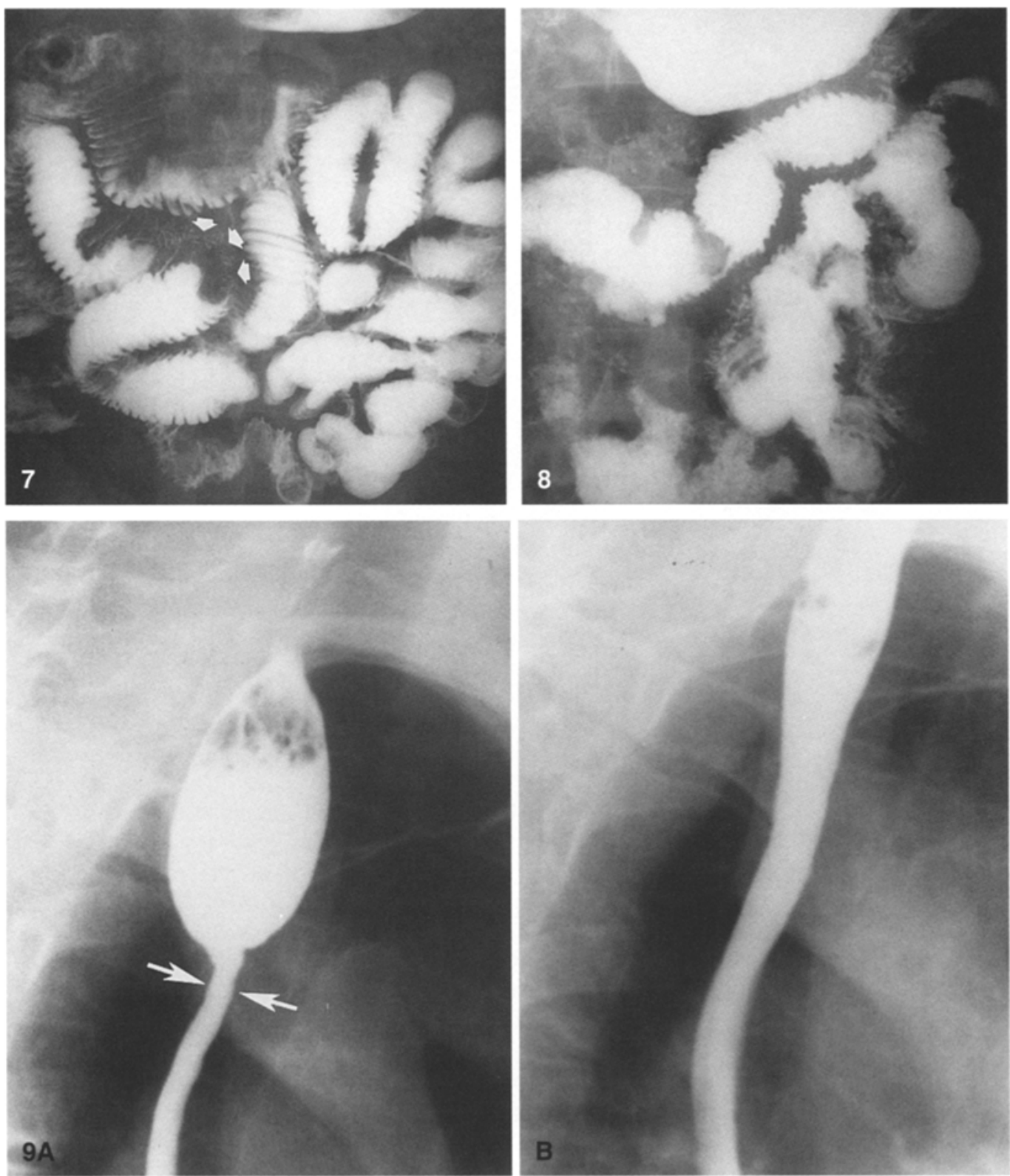

Fig. 7. Predominant subserosal disease. A 24-year-old man presented with abdominal pain and distention, nausea, and vomiting. Physical examination demonstrated ascites. Laboratory data revealed peripheral eosinophilia, and abdominal paracentesis showed eosinophilic ascites. Single-contrast small bowel follow-through examination (above) showed thickening of the folds and wall of the small bowel, dilatation, and segmental stenosis (arrowheads) of the small bowel and separation of bowel loops. Gastric biopsy was normal and a pyloric/duodenal bulb biopsy could not be done secondary to severe pyloric stenosis. Symptoms resolved with steroids.

Fig. 8. Prone SBFT in another patient with predominant subserosal disease demonstrates fold thickening of the jejunum, hypersecretion of the ileum, and separation of bowel loops. Abdominal CT revealed ascites, and abdominal paracentesis confirmed eosinophilic ascites.
Fig. 9. Eosinophilic esophagitis. A 35-year-old man presented with history of nausea, vomiting, and dysphagia, including an episode of esophageal obstruction. He had a history of atopic dermatitis and denied symptoms of gastroesophageal reflux disease. Laboratory data revealed a peripheral eosinophilia. Esophagoscopy showed a proximal esophageal stricture through which the endoscope could not be passed, and biopsies of the proximal esophagus demonstrated eosinophilic infiltration. UGI showed no evidence to support hiatal hernia or gastroesophageal reflux disease. The symptoms and esophageal stricture resolved with steroid therapy. A Barium esophagram shows an elongated, 5-mm caliber stricture of the proximal esophagus (arrows). B Barium esophagram in the same patient shows resolution of the proximal esophageal stricture after steroid therapy. 
Table 2. Etiology for a proximal esophageal stricture

\author{
Eosinophilic esophagitis \\ Radiation esophagitis \\ Caustic ingestion \\ Medication-induced esophagitis \\ Barrett's esophagus \\ Fungal infections \\ Skin disorders (epidermolysis bullosa, pemphigoid)
}

manifestations of the esophagus included strictures (10) and a cervical esophageal web (1).

\section{Conclusion}

We have presented a review of the literature and reported our experience with 25 patients with EG. It is important for the clinician to include EG in the differential diagnosis of abdominal and esophageal symptoms, especially when a patient presents with an allergic history and peripheral eosinophilia, because steroids result in a rapid resolution of symptoms. This will avoid the morbidity associated with the delay in diagnosis. Radiologists should consider this entity when bowel wall or fold thickening, strictures, or obstruction are found. It also should be included in the differential diagnosis of ascites of unknown etiology.

\section{References}

1. Naylor AR, Pollet JE. Eosinophilic colitis. Dis Colon Rectum 1985;28:615-618

2. Klein NC, Hargrove RL, Sleisenger MH, Jeffries GH. Eosinophilic gastroenteritis. Medicine 1970;49:299-319

3. Talley NJ, Shorter RJ, Philips SF, Zinsmeister AR. Eosinophilic gastroenteritis: a clinicopathological study of patients with disease of the mucosa, muscle layer, and subserosal tissues. Gut 1990;31:54-58

4. Burhenne JH, Carbone JV. Eosinophilic (allergic) gastroenteritis. Am J Roentgen 1966;96:332-338

5. Caldwell JH, Mekhjian HS, Hurtubise PE, Beman FM. Eosinophilic gastroenteritis with obstruction. Immunological studies of seven patients. Gastroenterology 1978;74:825-828

6. Caldwell JH, Tennenbaum JI, Bronstein HA. Serum IgE in eosinophilic gastroenteritis. Response to intestinal challenge in two cases. N Engl J Med 1975;292:1388-1390

7. Ureles AL, Alschibaja T, Lodico D, Stabins SJ. Idiopathic eosinophilic infiltration of the gastrointestinal tract, diffuse and circumscribed. Am J Med 1961;30:899-909

8. Goldberg HI, O'Kieffe D, Jenis EH, Boyce HW. Diffuse eosinophilic gastroenteritis. Am J Roentgenol Radium Ther Nuc Med 1973;119:342-351

9. Marshak RH, Lundner A, Maklansky D, Gelb A. Eosinophilic gastroenteritis. JAMA 1981;245:1677-1680
10. Vasquez Rodriquez JJ, Soleto Saez E, Sanchez Vega J, et al. Pancreatitis and eosinophilic gastroenteritis. Int Surg 1973;58:415419

11. Steffen RM, Wyllie R, Petras RE, et al. The spectrum of eosinophilic gastroenteritis: report of six pediatric cases and review of the literature. Clin Pediatr 1991;30(7):404-411

12. Teele RL, Katz AJ, Goldman H, Kettle RM. Radiographic features of eosinophilic gastroenteritis (allergic gastroenteropathy) of childhood. AJR 1979;132:575-580

13. Leinbach GE, Rubin CE. Eosinophilic gastroenteritis: a simple reaction to food allergens? Gastroenterology 1970;59:874-889

14. Vitellas KM, Bennett WF, Bova JG, Johnson JC, Caldwell JH, Mayle JE. Idiopathic eosinophilic esophagitis. Radiology 1993; 186:789-793

15. Picus D, Frank P. Eosinophilic esophagitis. AJR 1981;136:1001 1003

16. Feczko PJ, Halpert RD, Zonca M. Radiologic abnormalities in eosinophilic esophagitis. Gastrointest Radiol 1985;10:321-324

17. Jona JZ, Belin RP, Burke JA. Eosinophilic infiltration of the gastrointestinal tract in children. Am J Dis Child 1976;130:11361139

18. Partyka EK, Sanowski RA, Kozarek RA. Colonscopic features of eosinophilic gastroenteritis. Dis Colon Rectum 1980;23:353-356

19. Chisholm JC, Martin HI. Eosinophilic gastroenteritis with rectal involvement: case report and a review of the literature. $J$ Natl Med Assoc 1981;73:749-753

20. Kaplan SM, Goldstein F, Kowlessar, OD. Eosinophilic gastroenteritis: report of a case with malabsorption and protein-losing enteropathy. Gastroenterology 1970;58:540-545

21. Robert F, Omura E, Durant JR. Mucosal eosinophilic gastroenteritis with systemic involvement. Am J Med 1977;62:139-143

22. Gregg JA, Utz DC. Eosinophilic cystitis associated with eosinophilic gastroenteritis. Mayo Clin Proc 1974;49:185-187

23. Jacobsen LB. Diffuse eosinophilic gastroenteritis. An adult form of allergic gastroenteropathy. Am J Gastroenterol 1970;54:580588

24. Brostoff J, Craig O, Everest M. Eosinophilic gastroenteritis. Br J Surg 1970;57:653-657

25. Gilinsky NH, Kohler RG. Idiopathic obstructive eosinophilic enteritis with raised IgE: response to oral disodium cromoglycate. Postgrad Med J 1982;58:239-243

26. Heatley RV, Harris A, Atkinson M. Treatment of a patient with clinical features of eosinophilic gastroenteritis and polyarteritis nodosa with oral sodium cromoglycate. Dig Dis Sci 1980;25:470472

27. Heddle SB, Parrott KB, Paloschi GP, Prentice RS, Persyko L, Beck IT. Diffuse eosinophilic gastroenteritis. Can Med Assoc J 1969;100:554-559

28. Agertoft A, Husby S, Host A. Intestinal perforation in a two-yearold child with eosinophilic gastroenteritis. Acta Paediatr Scand 1991;80:389-391

29. Russell JYW, Evangelou G. Eosinophilic infiltration of the stomach and duodenum complicated by perforation. Postgrad Med J 1965;41:30-33

30. Felt-Bersma RJF, Meuwissen SGM, van Velzen D. Perforation of the small intestine due to eosinophilic gastroenteritis. Am J Gastroenterol 1984;79:442-445

31. Laufer I. A simple method for routine double-contrast study of the upper gastrointestinal tract. Radiology 1975;117:513-518

32. MacCarty RL, Talley NJ. Barium studies in diffuse eosinophilic gastroenteritis. Radiology 1990;15:183-187

33. Matzinger MA, Daneman A. Esophageal involvement in eosinophilic gastroenteritis. Pediatr Radiol 1983;13:35-38

34. Lee RG. Marked eosinophilia in esophageal mucosal biopsies. Am J Surg Pathol 1985;9:475-479 